\title{
Methotrexate Toxicity During Treatment of Chronic Plaque Psoriasis: A Case Report and Review of the Literature
}

\author{
Anja Weidmann • Amy C. Foulkes • N. Kirkham • \\ N. J. Reynolds
}

To view enhanced content go to www.dermtherapy-open.com

Received: May 1, 2014 / Published online: June 19, 2014

(C) The Author(s) 2014. This article is published with open access at Springerlink.com

\section{ABSTRACT}

Methotrexate continues to be one of the most widely used systemic immunosuppressive agents in dermatology. In addition to the important, well-characterized adverse effects such as hepatotoxicity and myelosuppression, methotrexate may induce a number of rare cutaneous adverse events including methotrexate-induced ulceration. We present a case of methotrexate-induced cutaneous ulceration in a patient with chronic plaque

Electronic supplementary material The online version of this article (doi:10.1007/s13555-014-0056-z) contains supplementary material, which is available to authorized users.

A. Weidmann $(\varangle) \cdot$ A. C. Foulkes

The Dermatology Centre, Salford Royal NHS

Foundation Trust, Salford M6 8HD, UK

e-mail: anja.weidmann@srft.nhs.uk

\section{N. Kirkham}

Department of Cellular Pathology, Royal Free London NHS Foundation Trust, London NW3 QG, UK

\section{N. J. Reynolds}

Institute of Cellular Medicine (Dermatology),

2nd Floor, William Leech Building, Medical School,

Newcastle University, Newcastle NE2 4HH, UK psoriasis occurring during long-standing methotrexate therapy. Withdrawal of the drug and appropriate skin care led to rapid healing of the ulceration and the agent was later safely reintroduced for the ongoing management of the patient's chronic plaque psoriasis. Review of the literature demonstrates cases of this important rare adverse event, primarily occurring in patients with chronic plaque psoriasis, induced by triggers such as accidental overdose or introduction of an interacting agent. Cutaneous ulceration typically precedes other markers of toxicity. Active treatment with folinic acid (calcium leucovorin) may be required. Early recognition, prompt cessation of methotrexate, and appropriate treatment minimizes morbidity. Dermatologists need to be alert to the possibility of cutaneous adverse events associated with methotrexate therapy, aware of potential drug interactions, and confident in the management of methotrexate toxicity.

Keywords: Adverse event; Cutaneous ulceration; Dermatology; Folinic acid (calcium leucovorin); Methotrexate; Psoriasis 


\section{INTRODUCTION}

Introduced in the 1950s, methotrexate continues to be one of the most widely used systemic immunosuppressive agents in dermatology [1, 2]. Whilst awareness of important potential adverse events such as hepatotoxicity, myelosuppression, and pulmonary fibrosis are reflected in robust guidelines for dosing and monitoring of treatment [3], other adverse events including cutaneous ulceration remain rarely reported and poorly characterized. Cutaneous ulceration may play a crucial role as an early clinical sign of impending systemic toxicity [4]. Although rare, it is of primary importance that dermatologists remain alert to cutaneous indicators of methotrexate toxicity, are aware of risk factors that may affect drug metabolism and are confident in the management of methotrexate overdose.

We present a case of methotrexate toxicity manifesting with cutaneous ulceration and review the literature, highlighting practice points relevant to dermatology.

\section{METHOTREXATE}

\section{Uses}

Methotrexate is licensed for the treatment of severe psoriasis, psoriatic arthritis, rheumatoid arthritis, and a number of malignancies, including: childhood acute lymphoblastic leukemia, lymphoproliferative disorders, choriocarcinoma, and various solid organ tumors. In addition, methotrexate is an abortifacient used in early and ectopic pregnancy and is used off-license in a host of dermatological conditions including atopic eczema [5, 6] and bullous pemphigoid [1], as well as non-dermatological conditions, including: Crohn's disease, systemic lupus erythematosus, and myositis.

Methotrexate can be used as monotherapy or in combination with other agents including biologic therapies $[7,8]$. Combination therapy with methotrexate and infliximab has been reported for the treatment of SAPHO syndrome (synovitis, acne, pustulosis, hyperostosis, and osteitis) [9], pityriasis rubra pilaris [10], recalcitrant chronic plaque psoriasis [11], and erythrodermic psoriasis [12]. For the treatment of chronic plaque psoriasis, combination therapy of etanercept with methotrexate led to improved disease control in a randomized, double-blinded, placebo-controlled clinical trial [13] as well as in reporting by individual centers [14]. Combination therapy of infliximab with methotrexate led to dose reduction of infliximab when compared with combinations of infliximab and azathioprine [15], increased dosing intervals [12], and appears to be well tolerated when compared with methotrexate monotherapy [16].

It is postulated that the addition of methotrexate to biologic therapy may allow the maintenance of therapeutic benefit through the reduction of formation of anti-infliximab autoantibodies [11]. While this has not been conclusively demonstrated in dermatology patients [17], evidence in rheumatology cohorts suggests that addition of immunosuppressive drugs to biologic therapy does reduce the induction of anti-tumor necrosis factor antibodies [17].

\section{Mechanism of Action}

Methotrexate may be administered orally, subcutaneously, or intramuscularly. Methotrexate is primarily bound to serum albumin and excreted unchanged in the urine 
[1]. The drug enters cells via the reduced folate carrier [18] where it is modified by the addition of up to seven glutamates (methotrexate polyglutamate; $\mathrm{MTXPG}_{1-7}$ ), catalyzed by the enzyme folylpolyglutamate synthetase [18]. The MTXPGs (particularly longer chain polyglutamates, i.e., $\mathrm{MTXPG}_{4-7}$ ) are not as easily transported out of cells. They increase the intracellular half-life of the drug and act on several key enzymes, including dihydrofolate reductase and thymidylate synthase, which are involved in the pyrimidine synthesis essential for DNA replication [18].

Decreased DNA synthesis in activated T cells and keratinocytes may be one of the mechanisms of action of the drug in psoriasis vulgaris. However, methotrexate affects other pathways, including the synthesis of adenosine via inhibition of the enzyme 5-aminoimidazole4-carboxamide ribonucleotide transformylase. This leads to a net increase in the release of adenosine which acts as an anti-inflammatory mediator [19].

There is considerable inter-individual variation in toxicity and response to methotrexate therapy. To date, one of the largest and most comprehensive pharmacogenetic studies in psoriasis evaluated the role of single nucleotide polymorphisms (SNPs) on treatment response to methotrexate [20], demonstrating SNPs in the genes encoding efflux transporter proteins are associated with response to methotrexate. Evaluation of a smaller cohort of patients demonstrated a folate carrier allele to be associated with methotrexate toxicity [21]. In rheumatoid arthritis, the role of SNPs in genes coding for intracellular polyglutamates has been evaluated [22] and have been found to be associated with efficacy of treatment while detectable red blood cell levels of MTXPG $_{4-7}$ have been shown to predict clinical response [23, 24].
Pharmacogenomics may yet play a greater role in the prediction of efficacy and toxicity of methotrexate, with identification of genetic markers for pre-treatment testing [25]. However, at present markers have only been applied in small cohorts with limited reproducibility in daily practice [26].

\section{Toxicity of Methotrexate}

In dermatology, typical starting doses of oral methotrexate range from 5 to $15 \mathrm{mg}$ weekly, escalating every 2-4 weeks to a maximum of around $25 \mathrm{mg}$ weekly [27]. Risk of toxicity with low-dose methotrexate treatment is felt to be low with no evidence of increased carcinogenicity within the dermatology population [28]. Providing monitoring remains satisfactory, there is no defined maximum duration of treatment with many patients remaining on the drug for long periods of 10-15 years [27].

Concomitant folic acid supplementation alongside methotrexate has been shown to reduce the incidence of gastrointestinal side effects, liver dysfunction, and improve continuance of treatment [29]. Higher supplementation regimens have been posited to reduce the efficacy of methotrexate $[30,31]$, but a minimum dose of $5 \mathrm{mg}$ weekly (given on any day except that of methotrexate dosing) is recommended [3].

Robust guidelines exist for the screening and monitoring of patients on methotrexate for dermatological and rheumatological indications [3, 32]. Well-recognized side effects include: nausea/vomiting, folic acid deficiency, myelosuppression, hepatotoxicity (both as an acute transaminitis and as chronic fibrosis/ cirrhosis), and pulmonary toxicity. Of these, bone marrow toxicity can occur after long-term treatment, but also at low doses at the initiation 
of therapy. A first dose of no more than $5 \mathrm{mg}$ with repeat full blood count prior to the second dose is recommended in treatment naïve patients [3, 32].

Risk of hepatotoxicity is increased by concurrent alcohol consumption, obesity, hepatitis, diabetes mellitus, and cumulative doses of more than $3 \mathrm{~g}$ of methotrexate [32]. Monitoring for liver toxicity may include regular serum liver function testing, serial measurement of procollagen III peptide, liver biopsy, and/or transient elastography scanning [33], although robust evidence to support the utility of one or more potential biomarkers of liver toxicity is lacking.

A key cause of toxicity is concurrent treatment with interacting agents that decrease protein binding or reduce renal clearance. Some interactions (e.g., for proton-pump inhibitors) have been reported mainly during high-dose methotrexate regimens [34] while others [such as trimethoprim, non-steroidal anti-inflammatory drugs (NSAIDs), and salicylates] have also been reported in patients on low-dose methotrexate [35]. Patients and physicians should be alert to possible interactions and regularly review additional medication use.

A number of cutaneous adverse events have also been described, including: mucositis [36], erythema multiforme [37], Stevens-Johnson syndrome [38], toxic epidermal necrolysis [39, 40], photosensitivity [41], 'recall reactions' of previous photodermatoses [42], exfoliative dermatitis [43, 44], and ulceration/skin necrosis [4]. Of these, mucositis and photosensitivity are usually dose-related and more commonly associated with high-dose regimens used in chemotherapy than in low-dose therapy used in dermatology $[36,42]$.

Erythema multiforme, Stevens-Johnson syndrome, and toxic epidermal necrolysis are idiosyncratic immune reactions where the full mechanism is not yet understood. Drug interactions and genetic predisposition are felt to influence the risk of development of severe adverse drug reactions, but are not present in all cases [45].

\section{CASE REPORT}

We report an 83-year-old female with longstanding severe chronic plaque psoriasis who requested urgent assessment with a 3-week history of oral ulceration and a 2-week history of a flare of her psoriasis.

She had been established on methotrexate therapy for more than 10 years. During the course of the therapy, her dose had gradually escalated to $25 \mathrm{mg}$ once weekly. Folic acid (5 mg) was taken once weekly on a separate day. Her cumulative dose of methotrexate was more than $7 \mathrm{~g}$.

The patient suffered comorbidities, including hypertension and congestive cardiac failure. Prior to this presentation, she required hospitalization for the treatment of cardiac failure. Treatment comprised an increase in the dose of her furosemide. Her other medications were isosorbide mononitrate, lisinopril, Adcal- $\mathrm{D}_{3}$, and quinine sulfate. No new medications were instituted.

On attendance the patient was systemically well and afebrile. Clinically she had oral erosions to the buccal mucosa (Fig. 1) and large, painful, inflamed, and ulcerated psoriatic plaques each with a prominent tender erythematous weepy inflamed edge (Fig. 2).

Routine bloods demonstrated a low platelet count of 109 (normal range $150-400 \times 10^{9} / \mathrm{L}$ ). Renal function was normal and methotrexate level measured at the time of admission was undetectable. 


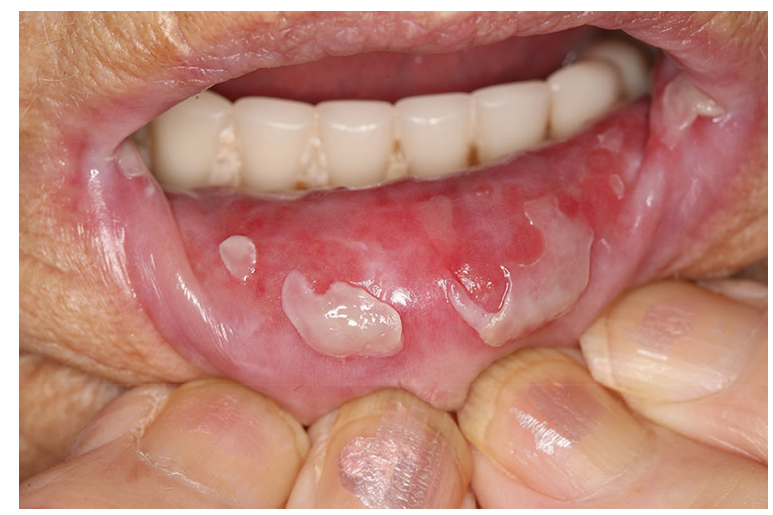

Fig. 1 Oral erosions

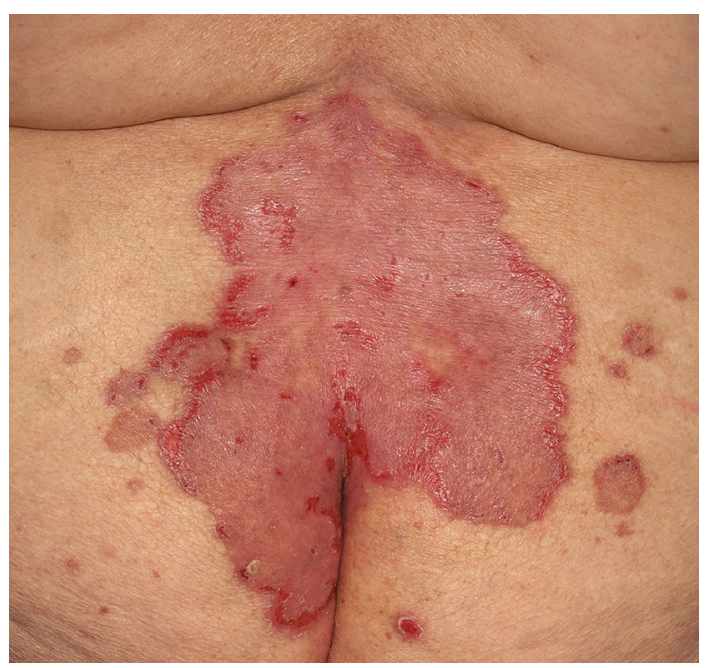

Fig. 2 Large painful ulcerated plaques of psoriasis

Skin biopsy taken from the edge of an inflamed plaque on the trunk demonstrated attenuation of relatively atrophic epidermis with overlying parakeratotic scale and apoptotic keratinocytes (Figs. 3, 4).

A diagnosis of methotrexate toxicity was made; the drug was discontinued and topical therapy commenced. Symptoms and signs resolved within 2 weeks following withdrawal of methotrexate. Treatment was reintroduced at a lower dose of $10 \mathrm{mg}$ of methotrexate weekly with concomitant folic acid supplementation ( $5 \mathrm{mg}$ daily for 6 days of the week, omitted on

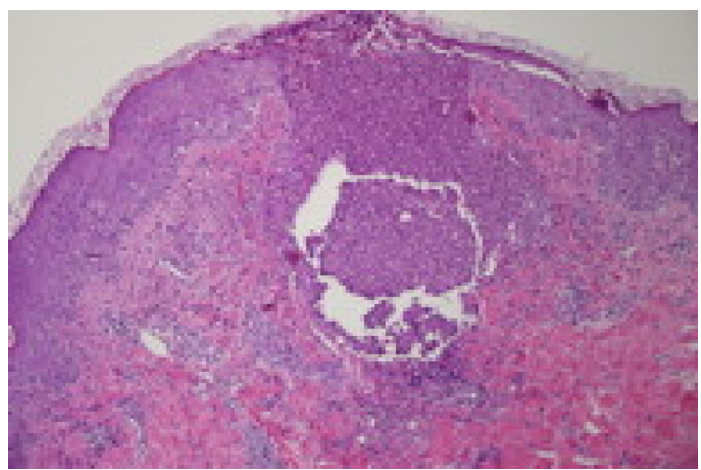

Fig. 3 Histology from skin biopsy taken from the edge of an inflamed plaque on the trunk

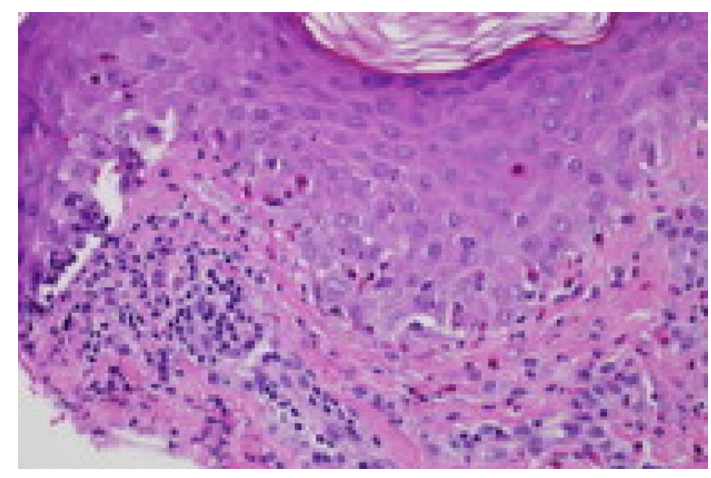

Fig. 4 Histology from skin biopsy taken from the edge of an inflamed plaque on the trunk

day of methotrexate dose) with no adverse effects.

Informed consent was obtained from the patient for being included in the study and for publication of the images.

\section{DISCUSSION}

\section{Methotrexate-Induced Cutaneous Ulceration}

Ulceration of the skin was well-recognized with aminopterin [46], the precursor to methotrexate, and was also reported shortly after the introduction of the methotrexate as a treatment for psoriasis [47]. It has been at the onset of treatment [48], during long-term 
methotrexate therapy [49], and as a presenting feature of accidental overdose [50].

The exact incidence of methotrexate-induced skin ulceration is difficult to assess, but appears to be rare. Roenigk et al. [47] noted ulceration in 6 of 204 patients treated with methotrexate, while Lawrence and Dahl [4] reported seven patients who had presented over the preceding 17-year period, but do not indicate what proportion of cases this represented.

In 1996, a literature review by Pearce and Wilson [51] identified 47 cases of methotrexate-induced skin ulceration reported between 1951 and 1967, and a further 17 cases (including two of their own patients and those by Roenigk et al. [47] and Lawrence and Dahl [4]) between 1967 and 1996. A PubMed search using the terms "methotrexate" AND "ulceration" identified a further 18 cases published after 1996 (Table 1) [48-50, 52-61].

Perhaps surprisingly, most cases of methotrexate-induced ulceration have been reported in patients with psoriasis on low-dose treatment rather than in those on high-dose oncology regimens. It is postulated that that the increased proliferation of keratinocytes within psoriatic plaques makes them particularly vulnerable to the effects of folate-antagonism. However, Lawrence and Dahl [4] described two patterns of methotrexate-induced ulceration: type 1 as superficial ulceration of existing psoriatic plaques and type 2 as ulceration of non-psoriatic skin. Isolated cases of methotrexate-induced ulceration in patients without a history of psoriasis have been reported including patients on low-dose treatment for rheumatoid arthritis $[52,56]$ and patients undergoing treatment for mycosis fungoides [60].

Patients may present with isolated cutaneous lesions or with other signs of methotrexate toxicity including mucositis, liver dysfunction, and/or myelosuppression. Psoriatic plaques and/or normal skin becomes painful, erythematous, and superficially eroded. Early cutaneous ulceration may be mistaken for a flare of psoriasis leading to erroneous increase in methotrexate use by either patient [50] or physician [4].

Diagnostic biopsy is rarely required, however, histological features of methotrexate-induced ulceration include swollen keratinocytes with diminished nuclear and cytoplasmic staining and occasional vacuolated or dyskeratotic cells indicative of incipient epidermal necrosis [4]. Dermal changes include vascular dilatation and lymphocytic infiltrates $[4,58]$. Non-specific ulceration may also be present [58].

As with other methotrexate toxicity, skin ulceration has been described in the context of an adverse drug interaction when new medications are added to an existing methotrexate regimen [62]. Examples include; trimethoprim, amiodarone [63], furosemide [63], penicillin [63], and NSAIDs [51]. Additional risk factors include renal impairment and diabetes mellitus [50].

\section{Treatment of Methotrexate Toxicity}

Folate supplementation during treatment has been shown to reduce methotrexate toxicity [31] and improve compliance with treatment. There is considerable variation in the prescription of folic acid, however, a minimum of $5 \mathrm{mg}$ weekly (to be taken the day after methotrexate therapy) is recommended for UK practice [3].

In cases of ulceration, withdrawal of methotrexate supported by skin-directed therapy usually leads to rapid improvement in ulceration with many patients showing signs of healing within a few days; however, in isolated cases ulceration persists for years [4]. 


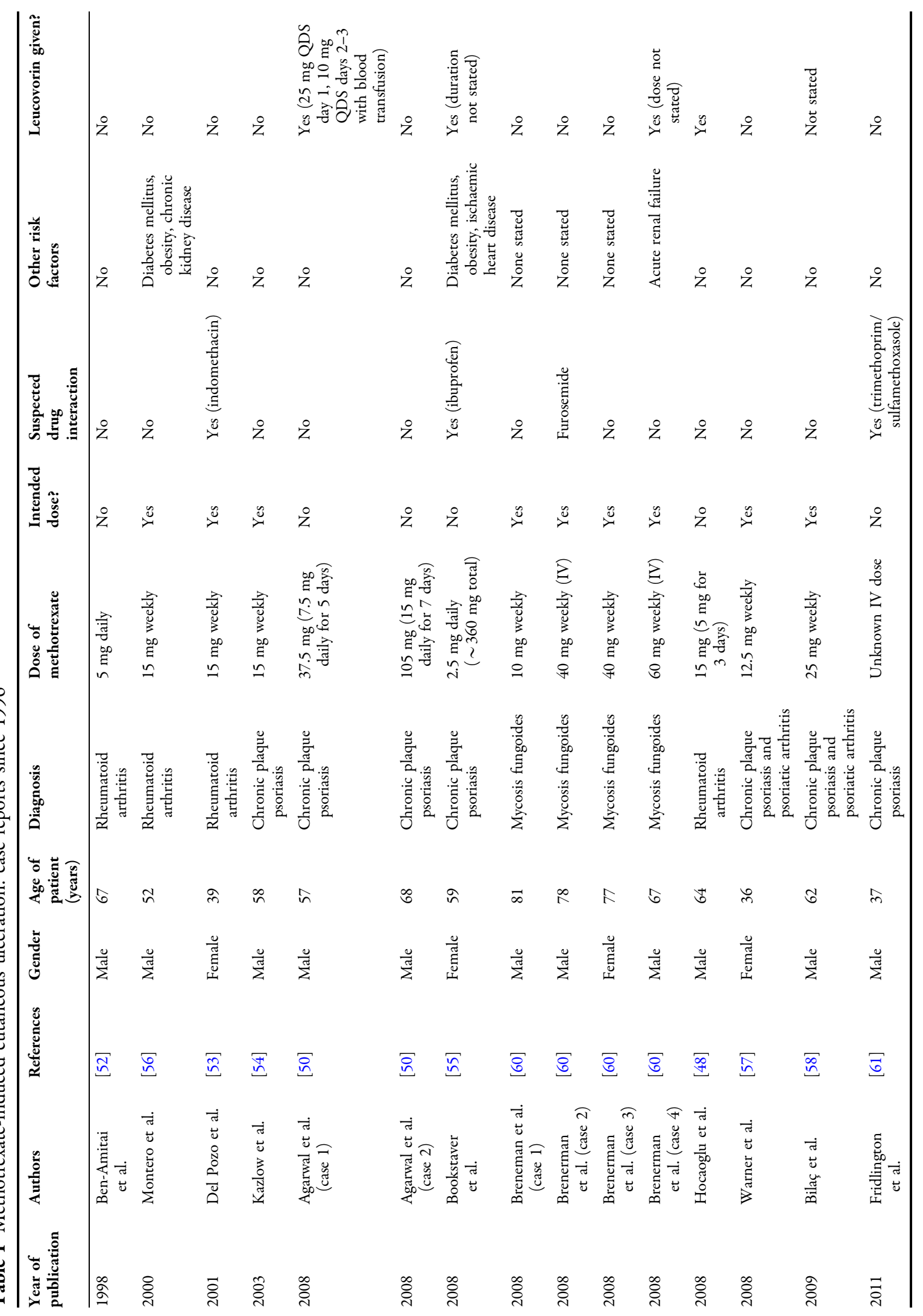




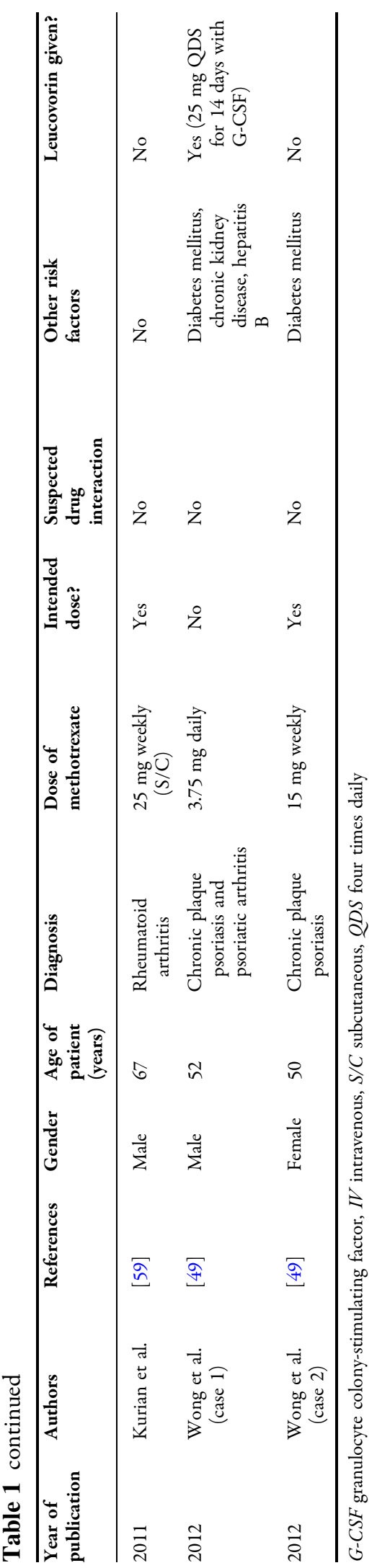

Folinic acid (calcium leucovorin) is used for treatment of methotrexate overdose including ulceration $[50,55]$. This treatment should be administered as soon as possible after exposure to methotrexate in $20 \mathrm{mg}$ doses (or $10 \mathrm{mg} / \mathrm{m}^{2}$ ) intravenously or intramuscularly, every $6 \mathrm{~h}$ until serum methotrexate concentration falls below $10^{-8} \mathrm{M}$ (assessed every $12-24 \mathrm{~h}$ ) or until the total dose of folinic acid is at least equal to the dose of methotrexate [32].

In patients with impaired renal function receiving high-dose methotrexate for cancer therapy who develop toxicity, glucarpidase has been used to hydrolyze methotrexate aiding clearance [64]. Glucarpidase is a recombinant bacterial enzyme and received Food and Drug Administration approval in 2012 [65]. It also has some limited application in cases of intrathecal methotrexate toxicity [65]. As yet there are no reports of this agent used within the dermatology population, however, there might be applications in cases of acute overdose.

\section{CONCLUSION}

Our case presented with typical manifestations of methotrexate-induced ulceration on a background of considerable, but previously well-tolerated, methotrexate use. Early recognition of cutaneous findings as a marker of methotrexate toxicity in the reported case allowed prompt cessation of the drug avoiding serious morbidity.

Methotrexate is a well-established element of the dermatology therapeutic arsenal governed by robust guidelines [32] for introduction and monitoring which aim to minimize patient risk. Pharmacogenomic evaluation of methotrexate may allow for future pre-treatment testing for risk of efficacy and toxicity. It is vital that dermatologists are confident in the recognition and management cutaneous and 
non-cutaneous manifestations of methotrexate toxicity in their own patients and those of other specialties.

\section{ACKNOWLEDGMENTS}

No funding or sponsorship was received for this study or publication of this article. ACF is a North West England MRC Clinical Research Training Fellow in Clinical Pharmacology and Therapeutics at The University of Manchester, funded by the Medical Research Council (Grant Number G1000417/94909), ICON, GlaxoSmithKline, AstraZeneca, and the Medical Evaluation Unit.

All named authors meet the ICMJE criteria for authorship for this manuscript, take responsibility for the integrity of the work as a whole, and have given final approval for the version to be published.

Conflict of interest. ACF has received educational support to attend conferences from or acted as a consultant for Pfizer, Abbvie, Leo Pharma, Novartis, and Janssen, all of which manufacture therapies used in the treatment of psoriasis. NJR has received consulting fees from Pfizer, consulting income (Newcastle University), research grants (Newcastle University), and travel support from Abbvie, AstraZeneca, Celgene, Genentech, Leo-Pharma Research Foundation, Novartis, Pfizer, and Stiefel GSK. AW and NK declare no conflict of interest.

\section{Compliance}

with

ethics

guidelines. Informed consent was obtained from the patient for being included in the study and for publication of the images.
Open Access. This article is distributed under the terms of the Creative Commons Attribution Noncommercial License which permits any noncommercial use, distribution, and reproduction in any medium, provided the original author(s) and the source are credited.

\section{REFERENCES}

1. Shen S, O'Brien T, Yap LM, Prince HM, McCormack CJ. The use of methotrexate in dermatology: a review. Australas J Dermatol. 2012;53(1):1-18.

2. Edmundson WF, Guy WB. Treatment of psoriasis with folic acid antagonists. AMA Arch Dermatol. 1958;78(2):200-3.

3. Chakravarty K, McDonald H, Pullar T, et al. BSR/ BHPR guideline for disease-modifying anti-rheumatic drug (DMARD) therapy in consultation with the British Association of Dermatologists. Rheumatology (Oxford). 2008;47(6):924-5.

4. Lawrence CM, Dahl MG. Two patterns of skin ulceration induced by methotrexate in patients with psoriasis. J Am Acad Dermatol. 1984;11(6):1059-65.

5. Weatherhead SC, Wahie S, Reynolds NJ, Meggitt SJ. An open-label, dose-ranging study of methotrexate for moderate-to-severe adult atopic eczema. Br J Dermatol. 2007;156(2):346-51.

6. Schram ME, Roekevisch E, Leeflang MM, Bos JD, Schmitt J, Spuls PI. A randomized trial of methotrexate versus azathioprine for severe atopic eczema. Journal of Allergy and Clinical Immunology, vol. 128. United States: Asthma \& Immunology. Published by Mosby, Inc; 2011. p. 353-9.

7. Stebbins WG, Lebwohl MG. Biologics in combination with nonbiologics: efficacy and safety. Dermatol Ther. 2004;17(5):432-40.

8. Rath T, Rubbert A. Drug combinations with methotrexate to treat rheumatoid arthritis. Clin Exp Rheumatol. 2010;28(5 Suppl 61):S52-7.

9. De Souza A, Solomon GE, Strober BE. SAPHO syndrome associated with hidradenitis suppurativa successfully treated with infliximab and 
methotrexate. Bull NYU Hosp Jt Dis. 2011;69(2): 185-7.

10. Barth D, Harth W, Treudler R, Simon JC. Successful treatment of pityriasis rubra pilaris (type 1) under combination of infliximab and methotrexate. J Dtsch Dermatol Ges. 2009;7(12):1071-4.

11. Warren RB, Brown BC, Carmichael AJ, Griffiths CE. Long-term control of recalcitrant psoriasis with combination infliximab and methotrexate. Clin Exp Dermatol. 2009;34(3):415-6.

12. Heikkilä H, Ranki A, Cajanus S, Karvonen SL. Infliximab combined with methotrexate as long-term treatment for erythrodermic psoriasis. Arch Dermatol. 2005;141(12):1607-10.

13. Gottlieb AB, Langley RG, Strober BE, et al. A randomized, double-blind, placebo-controlled study to evaluate the addition of methotrexate to etanercept in patients with moderate to severe plaque psoriasis. $\mathrm{Br} \mathrm{J}$ Dermatol. 2012;167(3): 649-57.

14. Driessen RJ, van de Kerkhof PC, de Jong EM. Etanercept combined with methotrexate for high-need psoriasis. Br J Dermatol. 2008;159(2): 460-3.

15. Dalaker M, Bonesrønning JH. Long-term maintenance treatment of moderate-to-severe plaque psoriasis with infliximab in combination with methotrexate or azathioprine in a retrospective cohort. J Eur Acad Dermatol Venereol. 2009;23(3):277-82.

16. Baranauskaite A, Raffayová $\mathrm{H}$, Kungurov NV, et al. Infliximab plus methotrexate is superior to methotrexate alone in the treatment of psoriatic arthritis in methotrexate-naive patients: the RESPOND study. Ann Rheum Dis. 2012;71(4): 541-8.

17. Atzeni F, Talotta R, Salaffi F, et al. Immunogenicity and autoimmunity during anti-TNF therapy. Autoimmun Rev. 2013;12(7):703-8.

18. Genestier L, Paillot R, Quemeneur L, Izeradjene K, Revillard JP. Mechanisms of action of methotrexate. Immunopharmacology. 2000;47(2-3):247-57.

19. Seitz M. Molecular and cellular effects of methotrexate. Curr Opin Rheumatol. 1999;11(3): 226-32.

20. Warren RB, Smith RLL, Campalani E, et al. Genetic variation in efflux transporters influences outcome to methotrexate therapy in patients with psoriasis. J Investig Dermatol. 2008;128(8):1925-9.
21. Campalani E, Arenas M, Marinaki AM, Lewis CM, Barker JNWN, Smith CH. Polymorphisms in folate, pyrimidine, and purine metabolism are associated with efficacy and toxicity of methotrexate in psoriasis [Erratum appears in J Invest Dermatol. 2008 Oct, 128(10), pp. 2545-6]. J Investig Dermatol. 2007;127(8):1860-7.

22. Hider SL, Bruce IN, Thomson W. The pharmacogenetics of methotrexate. Rheumatology (Oxford). 2007;46(10):1520-4.

23. Owen SA, Hider SL, Martin P, Bruce IN, Barton A, Thomson W. Genetic polymorphisms in key methotrexate pathway genes are associated with response to treatment in rheumatoid arthritis patients. Pharmacogenomics J. 2013;13(3):227-34.

24. Angelis-Stoforidis P, Vajda FJ, Christophidis N. Methotrexate polyglutamate levels in circulating erythrocytes and polymorphs correlate with clinical efficacy in rheumatoid arthritis. Clin Exp Rheumatol. 1999;17(3):313-20.

25. Weisman $\mathrm{MH}$, Furst DE, Park GS, et al. Risk genotypes in folate-dependent enzymes and their association with methotrexate-related side effects in rheumatoid arthritis. Arthritis Rheum. 2006;54(2):607-12.

26. Owen SA, Lunt M, Hider SL, Bruce IN, Barton A, Thomson W. Testing pharmacogenetic indices to predict efficacy and toxicity of methotrexate monotherapy in a rheumatoid arthritis patient cohort. Arthritis Rheum. 2010;62(12):3827-9.

27. Mrowietz U, de Jong EM, Kragballe K, et al. A consensus report on appropriate treatment optimization and transitioning in the management of moderate-to-severe plaque psoriasis. J Eur Acad Dermatol Venereol. 2014;28(4):438-53.

28. Naldi L. Malignancy concerns with psoriasis treatments using phototherapy, methotrexate, cyclosporin, and biologics: facts and controversies. Clin Dermatol. 2010;28(1):88-92.

29. Shea B, Swinden MV, Tanjong Ghogomu E, et al. Folic acid and folinic acid for reducing side effects in patients receiving methotrexate for rheumatoid arthritis. Cochrane Database Syst Rev. 2013;5: CD000951.

30. Chladek J, Simkova M, Vaneckova J, et al. The effect of folic acid supplementation on the pharmacokinetics and pharmacodynamics of oral methotrexate during the remission-induction period of treatment for moderate-to-severe plaque psoriasis. Eur J Clin Pharmacol. 2008; 64(4):347-55. 
31. Al-Dabagh A, Davis SA, Kinney MA, Huang K, Feldman SR. The effect of folate supplementation on methotrexate efficacy and toxicity in psoriasis patients and folic acid use by dermatologists in the USA. Am J Clin Dermatol. 2013;14(3):155-61.

32. Pathirana D, Ormerod AD, Saiag P, et al. European S3-guidelines on the systemic treatment of psoriasis vulgaris. J Eur Acad Dermatol Venereol. 2009;23(Suppl 2):1-70.

33. Montaudie H, Sbidian E, Paul C, et al. Methotrexate in psoriasis: a systematic review of treatment modalities, incidence, risk factors and monitoring of liver toxicity. J Eur Acad Dermatol Venereol. 2011;25(Suppl 2):12-8.

34. Bezabeh S, Mackey AC, Kluetz P, Jappar D, Korvick J. Accumulating evidence for a drug-drug interaction between methotrexate and proton pump inhibitors. Oncologist. 2012;17(4):550-4.

35. Bourré-Tessier J, Haraoui B. Methotrexate drug interactions in the treatment of rheumatoid arthritis: a systematic review. J Rheumatol. 2010;37(7):1416-21.

36. Troeltzsch $M$, von Blohn $G$, Kriegelstein $S$, Woodlock T, Gassling V, Berndt R. Oral mucositis in patients receiving low-dose methotrexate therapy for rheumatoid arthritis: report of 2 cases and literature review. Oral Surg Oral Med Oral Pathol Oral Radiol. 2013;115(5):e28-33.

37. Omoregie FO, Ukpebor M, Saheeb BD. Methotrexate-induced erythema multiforme: a case report and review of the literature. West Afr J Med. 2011;30(5):377-9.

38. Cuthbert RJ, Craig JI, Ludlam CA. Stevens-Johnson syndrome associated with methotrexate treatment for non-Hodgkin's lymphoma. Ulster Med J. 1993;62(1):95-7.

39. Primka EJ 3rd, Camisa C. Methotrexate-induced toxic epidermal necrolysis in a patient with psoriasis. J Am Acad Dermatol. 1997;36:815-8.

40. Gaigl Z, Seitz CS, Bröcker EB, Trautmann A. Methotrexate-induced toxic epidermal necrolysis-like skin toxicity. Eur J Dermatol. 2007;17(2):168-9.

41. Nedorost ST, Dijkstra JW, Handel DW. Drug-induced photosensitivity reaction. Arch Dermatol. 1989;125(3):433-4.

42. Khan AJ, Marghoob AA, Prestia AE, Spector IJ. Methotrexate and the photodermatitis reactivation reaction: a case report and review of the literature. Cutis. 2000;66(5):379-82.
43. Peters T, Theile-Ochel S, Chemnitz J, Söhngen D, Hunzelmann N, Scharffetter-Kochanek K. Exfoliative dermatitis after long-term methotrexate treatment of severe psoriasis. Acta Derm Venereol. 1999;79(5):391-2.

44. Doyle LA, Berg C, Bottino G, Chabner B. Erythema and desquamation after high-dose methotrexate. Ann Intern Med. 1983;98(5 Pt 1):611-2.

45. Pichler WJ, Naisbitt DJ, Park BK. Immune pathomechanism of drug hypersensitivity reactions. J Allergy Clin Immunol. 2011;127(3 Suppl):S74-81.

46. Gubner R. Effect of aminopterin on epithelial tissues. AMA Arch Derm Syphilol. 1951;64(6): 688-99.

47. Roenigk HH, Fowler-Bergfeld W, Curtis GH. Methotrexate for psoriasis in weekly oral doses. Arch Dermatol. 1969;99(1):86-93.

48. Hocaoglu N, Atilla R, Onen F, Tuncok Y. Early-onset pancytopenia and skin ulcer following low-dose methotrexate therapy. Hum Exp Toxicol. 2008;27(7):585-9.

49. Wong S-m, Chong YT, Thevarajah S, Baba R. Methotrexate toxicity presenting as ulcerated psoriatic plaques. Australas J Dermatol. 2012; 53(1):81-3.

50. Agarwal KK, Nath AK, Thappa DM. Methotrexate toxicity presenting as ulceration of psoriatic plaques: a report of two cases. Indian J Dermatol Venereol Leprol. 2008;74(5):481-4.

51. Pearce HP, Wilson BB. Erosion of psoriatic plaques: an early sign of methotrexate toxicity. J Am Acad Dermatol. 1996;35(5 Pt 2):835-8.

52. Ben-Amitai D, Hodak E, David M. Cutaneous ulceration: an unusual sign of methotrexate toxicity-first report in a patient without psoriasis. Ann Pharmacother. 1998;32(6):651-3.

53. Del Pozo J, Martinez W, Garcia-Silva J, Almagro M, Pena-Penabad C, Fonseca E. Cutaneous ulceration as a sign of methotrexate toxicity. Eur J Dermatol. 2001;11(5):450-2.

54. Kazlow DW, Federgrun D, Kurtin S, Lebwohl MG. Cutaneous ulceration caused by methotrexate. J Am Acad Dermatol. 2003;49(2):S197-8.

55. Bookstaver PB, Norris L, Rudisill C, DeWitt T, Aziz S, Fant J. Multiple toxic effects of low-dose methotrexate in a patient treated for psoriasis. Am J Health Syst Pharm. 2008;65(22):2117-21. 
56. Montero LC, Gomez RS, de Quiros JF. Cutaneous ulcerations in a patient with rheumatoid arthritis receiving treatment with methotrexate. J Rheumatol. 2000;27(9):2290-1.

57. Warner J, Brown A, Whitmore SE, Cowan DA. Mucocutaneous ulcerations secondary to methotrexate. Cutis. 2008;81(5):413-6.

58. Bilaç C, Türel Ermertcan A, Oztürkcan S, et al. Psoriatic plaque erosion: a rare side effect of methotrexate. J Eur Acad Dermatol Venereol. 2009; 23(3):335-6.

59. Kurian A, Haber R. Methotrexate-induced cutaneous ulcers in a nonpsoriatic patient: case report and review of the literature. J Cutan Med Surg. 2011;15(5):275-9.

60. Breneman DL, Storer TJ, Breneman JC, Mutasim DF. Methotrexate-induced cutaneous ulceration in patients with erythrodermic mycosis fungoides. Ther Clin Risk Manag. 2008;4(5):1135-41.
61. Fridlington JL, Tripple JW, Reichenberg JS, Hall CS, Diven DG. Acute methotrexate toxicity seen as plaque psoriasis ulceration and necrosis: a diagnostic clue. Dermatol Online J. 2011;17:2.

62. Nierenberg DW, Mamelok RD. Toxic reaction to methotrexate in a patient receiving penicillin and furosemide: a possible interaction. Arch Dermatol. 1983;119(6):449-50.

63. Reynolds NJ, Jones SK, Crossley J, Harman RR. Methotrexate induced skin necrosis: a drug interaction with amiodarone? BMJ. 1989; 299(6705):980-1.

64. Tuffaha HW, Al Omar S. Glucarpidase for the treatment of life-threatening methotrexate overdose. Drugs Today (Barc). 2012;48(11):705-11.

65. Green JM. Glucarpidase to combat toxic levels of methotrexate in patients. Ther Clin Risk Manag. 2012;8:403-13. 